\title{
Fire Resistance of Built-up Steel Section Completely Encased in Concrete
}

\author{
Nour Wehbi and Adnan Masri \\ Department of Civil and Environmental Engineering, Beirut Arab University, Lebanon
}

Received 18 July 2017; Accepted 11 November 2017

\begin{abstract}
Due to the increasing number of fire accidents that are able to leave behind great losses and complete collapse of structures, structural fire safety has become a major consideration in the design of high rise buildings. The aim of this research is to evaluate how certain factors can influence the critical time (fire resistance) of concrete encased dual Ishaped steel columns under fire loads using ABAQUS. The parameters that were considered are: the applied load level, stiffness of surrounding structure to column, section dimensions, concrete cover, and axial distance from concrete surface to longitudinal bars. In order to achieve the posted objective, numerical investigation using ABAQUS software was used. The analysis method considered is an alternative of Heat Transfer Method. This approximate method is based on dividing the section into layers at the location of experimentally recorded temperature-time histories and then linking load amplitude to its corresponding layer. In the study, twelve models were generated which belong to three types of sections subjected to high and low load levels, as well as, high and low surrounding stiffness. It was found that decreasing the load level and increasing the concrete cover have a big influence in increasing the critical time of the column. The effect of increasing the stiffness of the surrounding on reducing the critical time is insignificant and can be eliminated by designers. However, the effect of slenderness (section dimensions) on the restraining axial force requires further investigation.
\end{abstract}

Keywords :Built-up sections, dual I shaped column sections, composites, critical time, fire resistance rate, simulation.

\section{Introduction}

The catastrophic losses resulting from fire attacks have always been a subject of great interest to structural engineers. Most fire deaths occur due to the toxic effects of smoke before the structural collapse. However, the effect of fire on structural stability is critical in regard to safe evacuation and safe access for fire fighters, financial losses, and lost business. In order to handle such horrible situations as well as the global collapse of the structure, structural fire safety became one of the major considerations in the design of buildings specially the high rise ones. As a result, the usage of composite columns in high rise buildings have been increased in recent decades due to its dual advantage of significant load bearing capacity and seismic and fire resistance.

Moreover, because the perspective approaches based on standard fire testing or empirical calculations are found to be of non-realistic assessment in some cases [1], the recent trend is to use computer simulation for better evaluation of fire resistance of structural members. Another aspect is that the overview of the state of art shows that most researchers have studied the behavior of concrete filled steel tubular and hollow concrete filled steel tubular [3] under fire loads, while the behavior of built-up I-shaped sections partially or fully encased with concrete under fire are said to require more investigation [6].

\footnotetext{
*E-mail address: nour.wehbi93@gmail.com ISSN: $1791-2377$ @ 2017 Eastern Macedonia and Thrace Institute of Technology. All rights reserved. doi:10.25103/iestr.105.19
}

In this research, the behavior of built-up steel column section encased in concrete will be presented under the influence of transient heating according to ISO 834 standard fire curve considering several parameters. The influence of these factors on the generation of restraining forces, as well as, the critical time (fire resistance rate) is displayed and discussed. In addition, ABAQUS is used due to its excellent simulation ability in the domain [4].In fact, a simplified method of predefined-field assignment is used and based on experimental outputs taken from single HEA sections encased in concrete [6].

\section{Tested Sections}

The tested columns are made of double HEA steel sections (cross-intersected) totally encased in concrete and having $3 \mathrm{~m}$ height. The design of the composite section for flexure and shear was taken depending on the minimum requirements for fire resistance as mentioned in Eurocode 1994 [9].For instant, the sections were reinforced of 4 longitudinal bars of $12 \mathrm{~mm}$ diameter and $8 \mathrm{~mm}$ stirrups spaced at $150 \mathrm{~mm}$ near the column mid height and $100 \mathrm{~mm}$ near the edges.

\subsection{Material properties}

The concrete part is referred to normal weight concrete (NWC) of class C25/30, structural steel as S335, and reinforcement B500B [6].In fact, since this research is based on a previous experimental work done by [6] ,to be able to use a certain analysis method of interest, the material properties were kept the same. These material properties are shown in Tab. 1. 
Table 1 Mechanical properties of structural steel, reinforcement, and concrete

\begin{tabular}{l|c|c}
\hline \multicolumn{3}{|c}{ Composition } \\
$\begin{array}{l}\text { Structural } \\
\text { Steel }\end{array}$ & Yield Strength & $420 \mathrm{Mpa}$ \\
Reinforcement & Ultimate Strength & $516 \mathrm{Mpa}$ \\
\hline \multirow{2}{*}{ Concrete } & Ulield Strength & $512 \mathrm{Mpa}$ \\
& Compressive Strength & $38 \mathrm{Mpa}$ \\
\hline
\end{tabular}

\subsection{Section dimensions}

The tested sections are divided in to three categories referred to types $\mathrm{A}, \mathrm{B}$, and $\mathrm{C}$ as displayed in Fig. 1.The reason behind these variations is to consider the influence of slenderness (as we go from A to B) and the concrete cover as well as axial distance from the concrete surface to the longitudinal bars (as we go from B to C).

The concrete cover and axial distance to longitudinal bars are taken according to [9] satisfying certain fire resistance rates of interest. Similar to the material properties, these values are kept the same as found in [6] to be able to use the recorded temperature-time histories from the experimental work. The reinforcement steel area ratio was calculated according to (1) and found to be $0.01,0.0062$, and 0.0045 for types $\mathrm{A}, \mathrm{B}$, and $\mathrm{C}$ respectively. All these values belong to the range set by EN 1994 [0.003-0.04].

$$
0.003 \leq \frac{\text { As }}{\text { Ac }} \leq 0.04
$$

Where, As is the area of reinforcement and Ac is the area of concrete section.

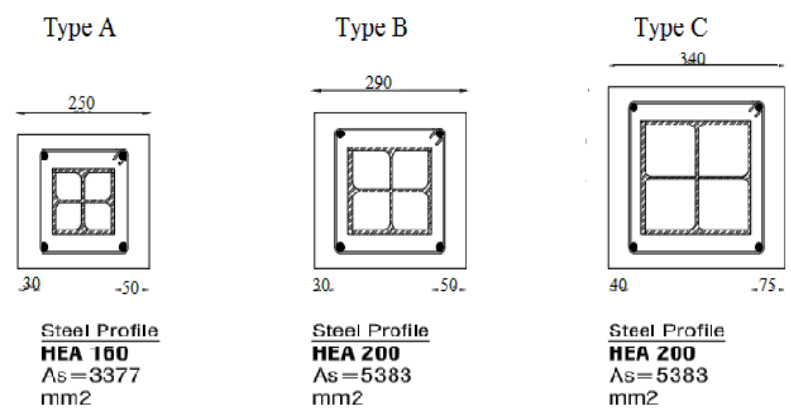

Fig. 1 Cross sections and longitudinal section of tested columns (mm)

\section{Numerical analysis}

In this research, twelve columns were generated using ABAQUS software based on the three sections of interest. Tab. 2 displays the boundary conditions and load level being applied for each of the columns. The load levels were taken 30 and $70 \%$ of the design buckling load at ambient temperature $\left(\mathrm{N}_{\mathrm{Rd}}\right)$ since the load levels in real composite members of steel and concrete are within this range.

$$
\mathrm{N}_{\mathrm{Rd}}=\mathrm{xN} \mathrm{N}_{\mathrm{Pl}, \mathrm{Rd}}
$$

Where, $\mathrm{x}$ is a coefficient can be computed from Eurocode buckling curves [9]. While, $\mathrm{N}_{\mathrm{Pl}, \mathrm{Rd}}$ is the plastic resistance to compression and can be computed according to EN1994 from (3).

$\mathrm{Npl,R}=$ Aafy $+0.85 \mathrm{fck}) \mathrm{cyl}$ Ac + Asfsk

Where, Aa, Ac, As are the areas of structural steel, concrete section, and reinforcing steel respectively. Whereas, fy, fck)cyl, and fsk are the yield strength of structural steel at ambient temperature, compressive strength of concrete cylinders at ambient temperature, and yield

\begin{tabular}{|c|c|c|c|c|}
\hline $\begin{array}{l}\text { Col. } \\
\text { No. }\end{array}$ & $\begin{array}{l}\text { Col. } \\
\text { type }\end{array}$ & $\begin{array}{l}\text { Boundary } \\
\text { Condition }\end{array}$ & $\begin{array}{c}\text { Applied Load } \\
]_{0}(K N)\end{array}$ & $\begin{array}{c}\text { EN } \\
\text { resistance } \\
\text { time (min) }\end{array}$ \\
\hline 1 & $\mathrm{~A}$ & Pinned & $30 \% * \mathrm{~N}_{\mathrm{Rd}}=601$ & R 90 \\
\hline 2 & A & Pinned & $70 \% * \mathrm{~N}_{\mathrm{Rd}}=1403$ & R 90 \\
\hline 3 & A & Fixed & $30 \% * \mathrm{~N}_{\mathrm{Rd}}=601$ & R 90 \\
\hline 4 & A & Fixed & $70 \% * \mathrm{~N}_{\mathrm{Rd}}=1403$ & R 90 \\
\hline 5 & B & Pinned & $30 \% * \mathrm{~N}_{\mathrm{Rd}}=878.09$ & R 90 \\
\hline 6 & B & Pinned & $70 \% * \mathrm{~N}_{\mathrm{Rd}}=2048.9$ & R 90 \\
\hline 7 & B & Fixed & $30 \% * \mathrm{~N}_{\mathrm{Rd}}=878.09$ & R 90 \\
\hline 8 & B & Fixed & $70 \% * \mathrm{~N}_{\mathrm{Rd}}=2048.9$ & R 90 \\
\hline 9 & $\mathrm{C}$ & Pinned & $30 \% * \mathrm{~N}_{\mathrm{Rd}}=1036.8$ & R 120 \\
\hline 10 & $\mathrm{C}$ & Pinned & $70 \% * \mathrm{~N}_{\mathrm{Rd}}=2419.8$ & R 120 \\
\hline 11 & $\mathrm{C}$ & Fixed & $30 \% * \mathrm{~N}_{\mathrm{Rd}} 1036.8$ & R 120 \\
\hline 12 & $\mathrm{C}$ & Fixed & $70 \% * \mathrm{~N}_{\mathrm{Rd}}$ & R 120 \\
\hline
\end{tabular}
strength of reinforcement at ambient temperature.

\section{ABAQUS Model}

ABAQUS is considered a powerful and advanced computational tool for modeling structural elements with both material and geometric nonlinear behavior. In this section, the main input data is presented.

\subsection{Material definition}

The material type that is assigned to both concrete and HEA parts is C3D8RT.This material stands for three dimensional, continuum, eight nodded element with reduced integration. The letter (T) makes it also a temperature element. The advantage of the reduced integration is to have only one integration point for each surface of the element and therefore reducing the amount of CPU time needed for analysis. However, the $12 \mathrm{~mm}$ longitudinal bars and $8 \mathrm{~mm}$ stirrups are generated as T3D2 which represents a two nodded truss (wire) element which can take temperature loads.

The steel reinforcement (longitudinal bars and stirrups) are defined as being fully embedded in the concrete (host region) according to European FRISCC workshop that was held in Germany on 19th February 2013.On the other hand, the interaction between the steel plates with the column is taken "Tie Constraint", where the plates are the master surfaces and the column top and bottom surfaces are slaves.

\subsection{Thermal action}

The thermal action is defined by using a simplified method based on predefined field assignment. This method is based on dividing the column section into vertical partitions through the location of thermocouples presented in experimental work done by [6]. After that, predefined fields of temperature-time histories are taken from the experimental work output, recorded by the thermocouples, and assigned to their corresponding

predefined partitioned field. Where, H1 represents the temperature-time history assigned to the HEA web, H2 for the flanges, and the remaining histories are related to concrete partitions. Fig. 2 shows the four sided thermal exposure and the various predefined histories assigned to 
each of the layers.

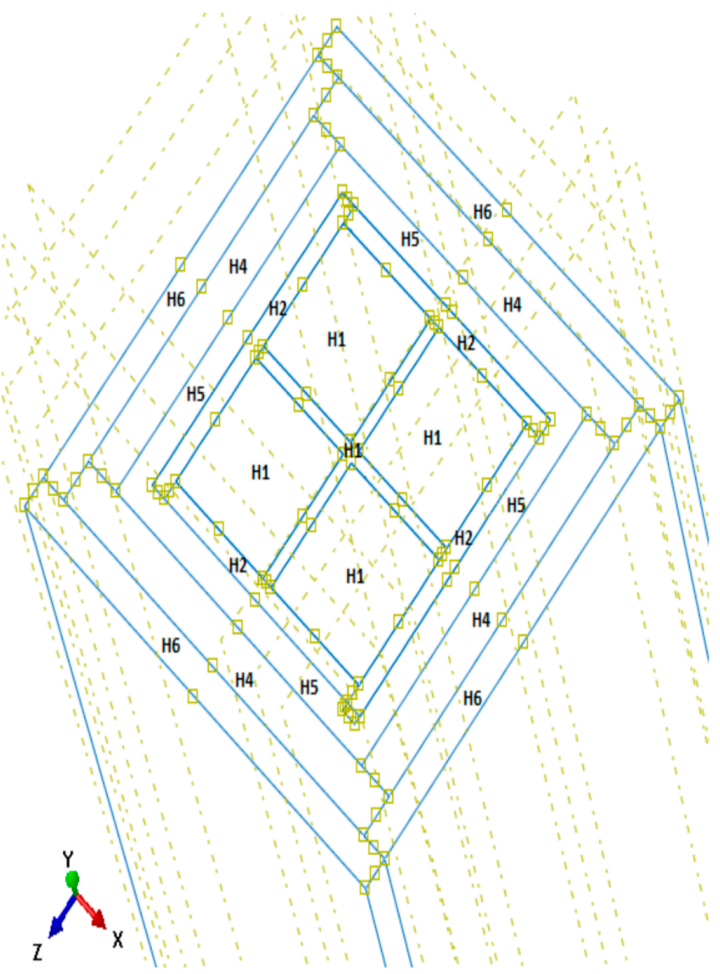

Figure 2 Predefined field histories of composite sections in ABAQUS

The coefficient of thermal expansion defined for structural steel, concrete, and reinforcement is dependent on Eurocode formulae [7] and [8].while working with Static General Method, there is no need to consider other thermal properties for the materials.

\subsection{Linear and non-linear behavior}

The linear behavior following Hooks law was defined in terms of the "Modulus of Elasticity" with temperature dependence data according to Eurocode 3(2005).However, Poisson ratio for the three materials is taken independent of temperature with values of $0.29,0.2$, and 0.3 for structural steel, concrete, and reinforcement respectively; according to Koddur 2004.In fact, there is no need to insert the density related data, as long as "Static General" is the chosen analysis method.

The non-linear behavior is characterized by degradation in material strength and stiffness. The reduction of elastic modulus and strength of concrete is due to degradation of stiffness at high temperature. While for steel, it is due to the movement of nuclei inside the iron atoms apart and thus reducing the bond strength between them.

The nonlinear behavior of both steel and concrete is introduced by choosing the "plastic-plasticity" method from ABAQUS library. For concrete $40 \mathrm{Mpa}$, these values are extracted from ASCE 1992 stress -strain temperature dependent formulas for normal strength concrete. For structural steel sections (420Mpa) and reinforced steel (512 $\mathrm{Mpa}$ ), these values are taken from EN3 (2005) stress-strain temperature dependent curves.

\section{Results}

\subsection{Restraining forces}

The restraining forces are axial forces generated by induced thermal stresses. For that reason, it can be seen that these forces increase gradually with exposure time until reaching a peak value after which degradation of steel strength and concrete deterioration starts. This loss of material stiffness leads to a reduction of restraining forces to reach the initial applied load value.

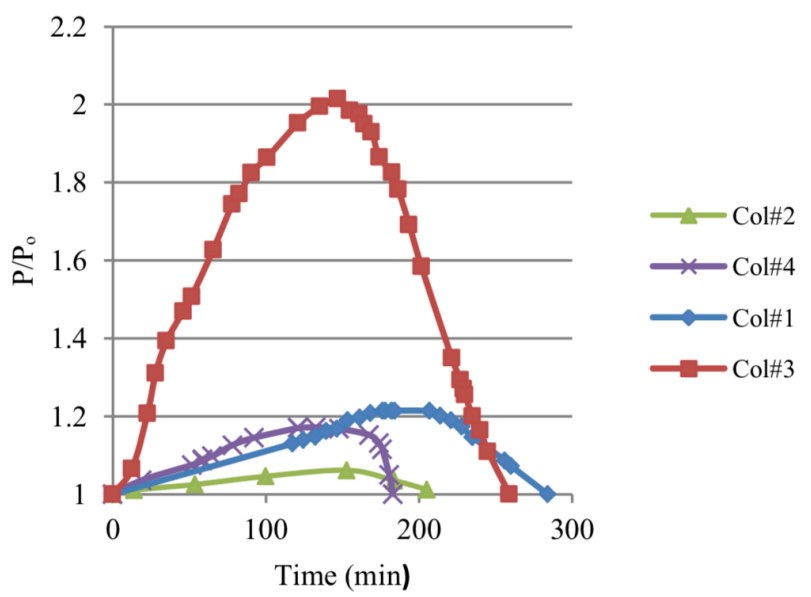

Fig. 3 Restraining forces of section type A

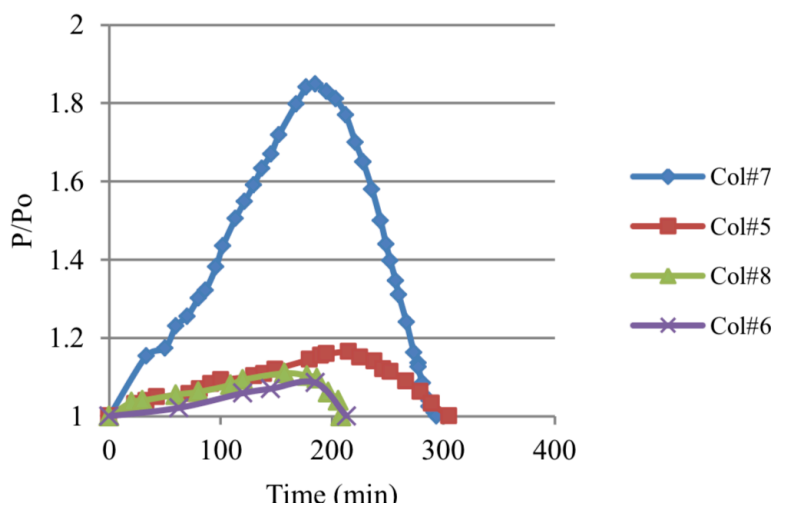

Fig. 4 Restraining forces of section type B

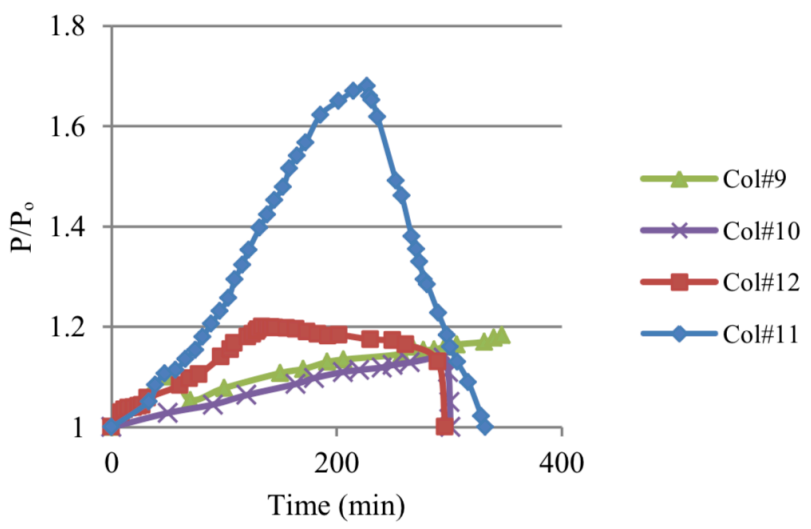

Fig. 5 Restraining forces of section type C

It is noticed that for the same section type and under the same boundary conditions, the higher load results in low values of restraining forces. This is due to the fact that increasing the load level allows higher deformation and thus more dissipation of induced stresses. However, increasing the stiffness of the boundaries for the same section and under same load level leads to higher restraining forces developed by the greater degree of rigidity and less thermal stresses dissipation.

The effect of slenderness (section dimensions) on restraining forces is not clearly understood in this research. 
For instant, the increase of section dimension under fixed boundary conditions and low load level generate a decrease in these values although deformations will be less. An example of that is the comparison among columns \# 3, 7, and 11.On the other hand, increasing the section dimensions under pin ended boundary condition and high load level results in higher induced forces, such as columns \#2,6, and10.

\subsection{Critical time (fire resistance rate)}

Critical time is defined as the time needed by the restraining forces to increase to a peak value due to the generation of induced thermal stresses and then fall again to the initial applied load because of the degradation in material strength and stiffness. Because this research is based on studying encased columns under transient heating, it was better to use the term critical time instead of fire resistance rate which is used in standard testing [6].

Table 3 Critical time of tested columns

\begin{tabular}{c|c|c}
\hline Section Type & Col. No. & Critical Time (min) \\
\hline \multirow{4}{*}{ A } & 1 & 284 \\
& 2 & 210 \\
& 3 & 259 \\
& 4 & $\mathbf{1 8 2}$ \\
\hline \multirow{4}{*}{ B } & 5 & 305 \\
& 6 & 213 \\
& 7 & 293 \\
& 8 & 209 \\
\hline \multirow{3}{*}{ C } & 9 & 346 \\
& 10 & 301 \\
\hline
\end{tabular}

Referring to Tab. 3, it is found that all columns are of good resistance to elevated temperature by having critical time greater than $180 \mathrm{~min}$ which is equivalent to 3 hours of exposure

Table 4 Load level effect on critical time

\begin{tabular}{c|c|c|c|c|c}
\hline \multirow{2}{*}{$\begin{array}{c}\text { Section } \\
\text { Type }\end{array}$} & \multicolumn{2}{|c|}{$\begin{array}{c}\text { Low Load } \\
\text { Level }\end{array}$} & \multicolumn{2}{c|}{$\begin{array}{c}\text { High Load } \\
\text { Level }\end{array}$} & \multirow{2}{*}{$\begin{array}{c}\text { Difference } \\
\text { \% }\end{array}$} \\
\cline { 2 - 5 } & $\begin{array}{c}\text { Col. } \\
\text { No. }\end{array}$ & $\begin{array}{c}\text { Critical } \\
\text { Time }\end{array}$ & $\begin{array}{c}\text { Col. } \\
\text { No }\end{array}$ & $\begin{array}{c}\text { Critical } \\
\text { Time }\end{array}$ & \\
\hline & 1 & 284 & 2 & 210 & 34.7 \\
A & 3 & 259 & 4 & 182 & 42.3 \\
\hline & 5 & 305 & 6 & 213 & 43.1 \\
B & 7 & 293 & 8 & 209 & 40.1 \\
\hline \multicolumn{7}{|c|}{ Mean Difference\% } \\
\hline
\end{tabular}

\begin{tabular}{|c|c|c|c|c|c|}
\hline \multirow{2}{*}{$\begin{array}{r}\text { Section } \\
\text { Type }\end{array}$} & \multicolumn{2}{|c|}{$\begin{array}{c}\text { Pinned } \\
\text { Boundary }\end{array}$} & \multicolumn{2}{|c|}{$\begin{array}{c}\text { Fixed } \\
\text { Boundary }\end{array}$} & \multirow[b]{2}{*}{$\begin{array}{c}\text { Difference } \\
\%\end{array}$} \\
\hline & $\begin{array}{l}\text { Col. } \\
\text { No. }\end{array}$ & $\begin{array}{l}\text { Critical } \\
\text { Time }\end{array}$ & $\begin{array}{l}\text { Col. } \\
\text { No }\end{array}$ & $\begin{array}{l}\text { Critical } \\
\text { Time }\end{array}$ & \\
\hline \multirow[t]{2}{*}{ A } & 1 & 284 & 3 & 259 & 9.7 \\
\hline & 2 & 210 & 4 & 182 & 15.4 \\
\hline \multirow[t]{2}{*}{ B } & 5 & 305 & 7 & 293 & 4.1 \\
\hline & 6 & 213 & 8 & 209 & 1.9 \\
\hline \multirow[t]{2}{*}{$\mathrm{C}$} & 9 & $>346$ & 11 & 332 & 4.2 \\
\hline & 10 & 301 & 12 & 295 & 2.2 \\
\hline \multicolumn{5}{|c|}{ Mean Difference \% } & 6.1 \\
\hline
\end{tabular}

Table 6 Section dimensions (type a and b) effect on critical time

\begin{tabular}{c|c|c|c|c}
\hline \multicolumn{2}{c|}{ Section B } & \multicolumn{2}{c|}{ Section A } & \multirow{2}{*}{ Difference \% } \\
\cline { 1 - 3 } $\begin{array}{c}\text { Col. } \\
\text { No. }\end{array}$ & $\begin{array}{c}\text { Critical } \\
\text { Time }\end{array}$ & $\begin{array}{c}\text { Col. } \\
\text { No. }\end{array}$ & $\begin{array}{c}\text { Critical } \\
\text { Time }\end{array}$ & \\
\hline 5 & 305 & 1 & 284 & 7.4 \\
6 & 213 & 2 & 210 & 1.5 \\
7 & 293 & 3 & 259 & 13.1 \\
8 & 209 & 4 & 182 & 14.8 \\
\hline \multicolumn{4}{c}{ Mean Difference \% } & $\mathbf{9 . 2 2}$ \\
\hline
\end{tabular}

Table 7 Section dimensions (type b and c) effect on critical time

\begin{tabular}{c|c|c|c|c}
\hline \multicolumn{2}{c|}{ Section C } & \multicolumn{2}{c|}{ Section B } & \multirow{2}{*}{ Difference \% } \\
\cline { 1 - 3 } Col. & Critical & Col. No. & $\begin{array}{c}\text { Critical } \\
\text { Time }\end{array}$ & \\
\hline 9 & $>346$ & 5 & 305 & 13.6 \\
10 & 301 & 6 & 213 & 41.3 \\
11 & 332 & 7 & 293 & 13.8 \\
12 & 295 & 8 & 209 & 41.115 \\
\hline \multicolumn{4}{c}{ Mean Difference \% } & $\mathbf{2 7 . 6}$ \\
\hline
\end{tabular}

According to Tab. 4, it can be noticed that the sections provide better resistance under low load level. For instant, it was found by calculating the mean difference that the critical time can be increased by about $31.4 \%$ by reducing the load level to $30 \% \mathrm{Nrd}$.

The effect of boundary condition was found to be insignificant because the usage of fixed boundary condition has led to a reduction of only $6.1 \%$ in the critical time. This reduction is not critical to be considered in design issues.Tab.5.

Comparing section type A with that of $\mathrm{B}$, it can be seen that columns of type B obtained higher critical time than those of A by only $9.22 \%$. This increase is due to the reduction in slenderness from 0.706 to 0.58 and found by increasing the steel inertia from HEA 160 to 200 Table-6. On the other hand, the usage of section $\mathrm{C}$ instead of $\mathrm{A}$ has led to significant increase in the critical time by $27.6 \%$.This increase is due to the increase of concrete cover from 50 to $75 \mathrm{~mm}$ and the axial distance from 40 to $50 \mathrm{~mm}$ resulting in lower slenderness $0.495<0.58$.

\subsection{Validation of ABAQUS Model}

In order to check the validity of the approximate method based on predefined temperature-time assignment, a comparison was made among the results obtained from experimental work done by [6] and an abaqus model. The experimental work in [6] studied the fire resistance rate of single-HEA steel sections totally encased in concrete under transient fire testing according to ISO 834 standard fire curve. In the numerical model, two columns were chosen to be tested using ABAQUS, representing the influence of axial and rotational restraints on the behavior and fire resistance of composite columns.

\subsubsection{Experimental work overview}

Fig.6, represents a detailed sketch of the experiment set up to better understand the test environment and conditions made by [6]. The system consisted of a restraining steel frame made to demonstrate the surrounding stiffness of a column. The connection between the restraining frame columns and the upper beams were made by using threaded rods M27, grade 8.8. Several hole locations were formed in the flanges of the upper beams allowing the assembly of 
column in different positions, resulting in variable beam spans and therefore surrounding stiffness. As a result, the stiffness of surrounding structures was considered at a low level of K13 and a high level of K128.

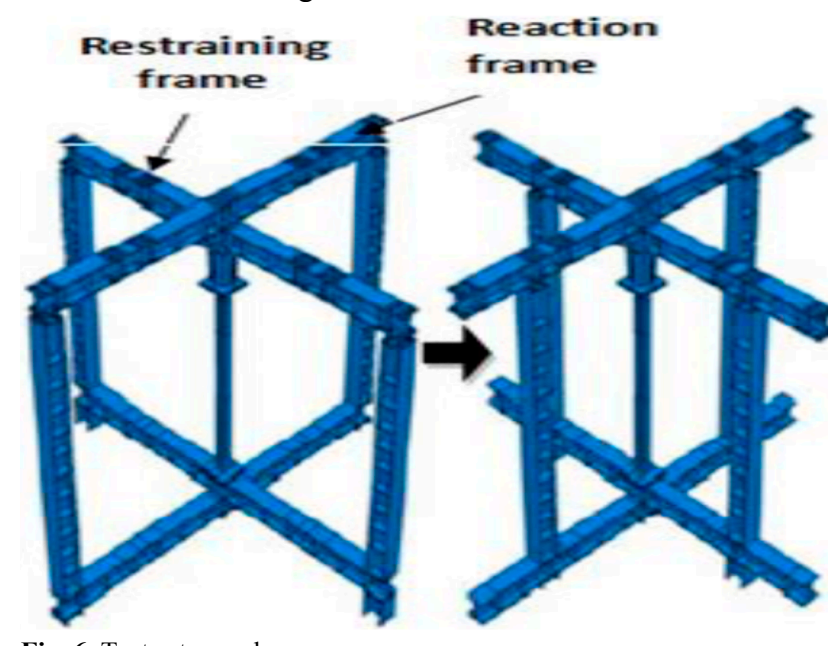

Fig, 6. Test set-up scheme

The tested columns were subjected to constant axial load provided by a $3 \mathrm{MN}$ capacity hydraulic jack controlled by a load cell.

\subsubsection{Section dimensions}

The columns considered in modeling stage were three meters high consisting of HEA 160 steel section and encased in $252 \times 260 \mathrm{~mm}$ reinforced concrete. The section was reinforced of 4 longitudinal bars having $12 \mathrm{~mm}$ diameter and $8 \mathrm{~mm}$ stirrups as shown in Fig. 7.
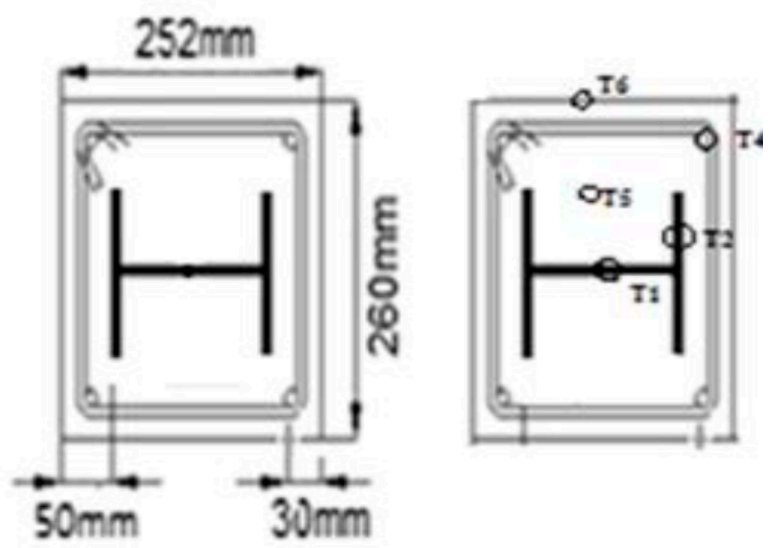

Fig. 7 Cross section of tested columns ( $\mathrm{mm})$ and location of thermocouples

\subsubsection{Abaqus model}

The material properties defined in the model were chosen from [6] and being as those presented in the part related to double - HEA sections; Tab. 1.

The temperature - time histories defined in the model were taken from the thermocouples record [6]. Also, the procedure followed in the modeling of this section was exactly as that discussed in ABAQUS MODEL to check the method validity.

The low stiffness of the surrounding structure (K13) was considered in the first model and defined as pin ended, while that of high stiffness (K128) as fixed ended.
Comparison of experimental and ABAQUS model results

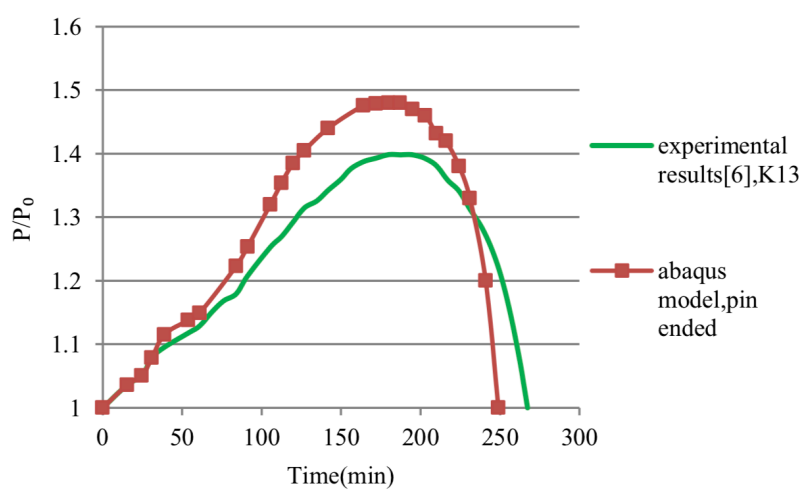

Fig. 8 Comparison of restraining forces in experimental and ABAQUS results (pin ended)

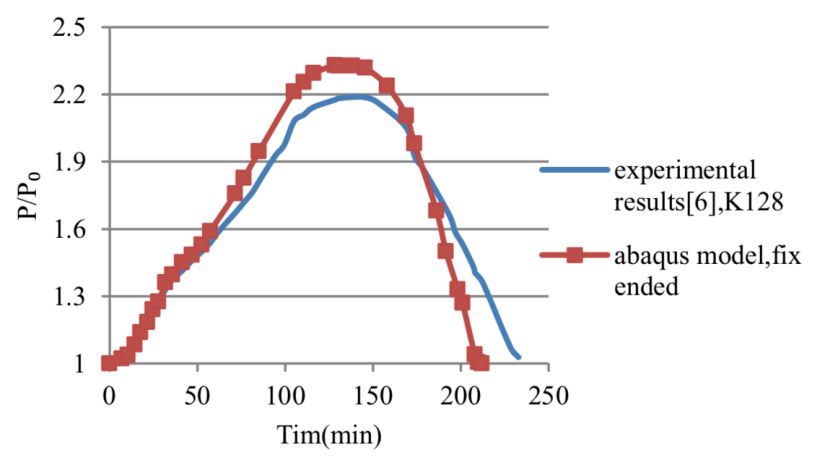

Fig 9 Comparison of restraining forces in experimental and ABAQUS results (fix ended)

Comparing the resistance time of fixed column with that of pin ended one, it is be obvious that the low stiffness one is providing a more survival time with a delay in the time needed for the beginning of material deterioration ;i.e.: around $168 \mathrm{mins}$ for pinned model and $110 \mathrm{mins}$ for the fixed one according to ABAQUS. It can be seen that the fixation boundary conditions give a better simulation of high stiffness surrounding than pinned one does for low stiffness .This is mainly because the pin boundary condition is considered more rigid than the real case, resulting in higher induced stresses and less thermal resistance time.

In general, this comparison acts as a proof for the ability of abaqus model and followed procedure in providing satisfying results with good accuracy that can be relied on.

\section{Research Limitations}

This research is based on the usage of some assumptions including: an eccentricity value of $10 \mathrm{~mm}$ to account for geometric imperfections and improper application of axial load. Also, the sections were studied under the influence of only some parameters. However, there are many other factors influencing the generation of restraining forces and critical time such as the column length. Moreover, in order to be able to use the temperature-time recorded data from thermocouples in the experimental work, the dimensions of the section, concrete cover, and material properties must be kept unchanged.

\section{Conclusions}

This research paved the way to developing a guide approach 
for designers when modeling composite columns of the mentioned type. For instant, this research provides engineers with the percentage of influence each factor has on the fire resistance of double HEA-concrete encased sections.

However, the influence of slenderness on the critical time was not clearly displayed due to the close values of slenderness. Moreover, the effect of other parameters must be taken in to consideration by working with optimization techniques like genetic algorithm, neural networks,etc.

Access article distributed under the terms of the Creative Commons Attribution License

\section{References}

1. Venkatesh Kodur, F.ASCE, Mahmud Dwaikat, and Rustin Fike,'High-Temperature Properties of Steel for Fire Resistance Modeling of Structures", J.Mater.Civ.Eng.2010.22:423-434.

2. Kai Xiang and Guo-hui Wang, " Experimental Study on Temperature Distribution of Concrete Filled Steel Tube Reinforced Concrete Square Short Columns", Procedia Engineering 71(2014)16-21.

3. Zygimantas Blazevicius and Audronis Kazimieras Kvedaras," Experimental Investigation in to Fire Resistance of HC-FST Columns under Axial Compression", Journal of Civil Engineering and Management-2007, Vol XIII, No 1, 1-10.

4. VenkateshKodur, "Properties of Concrete at Elevated Temperature”, ISRN Civil Engineering, 2014.

5. Hua Yang, Faqi Liu, Leroy Gardner ,'Post-fire behavior of slender reinforced concrete columns confined by circular steel tubes", J
Thin-Walled Structures 87(2015)12-29.

6. Joao Paulo C. Rodrigues, Antonio J.M. Correia, and Tiago A.C. Pires," Behavior of composite columns made of totally encased steel sections in fire", Journal of Constructional Steel Research 105(2015)97-106.

7. EN 1994-1-2 (2005): Eurocode 4: Design of composite steel and concrete structures-part 1-2: General rules-Structural fire design [Authority: The European Union per Regulation 305/2011, Directive98/ 34/ EC, Directive2004/ 18/ EC].

8. EN 1994-1-1. Design of composite steel and concrete structurespart 1-1: general rules and rules for buildings. Belgium: European Committee for Standardization: 2005.

9. EN 1993-1-1. Design of steel structures [Authority: The European Union Per Regulation 305/2011, Directive 98/34/EC, Directive 2004/18/EC] 